\title{
Vitamins $B_{2}, B_{6}$ and $B_{12}$ and Risk of New Colorectal Adenomas in a Randomized Trial of Aspirin Use and Folic Acid Supplementation
}

\author{
Jane C. Figueiredo ${ }^{1}$, A. Joan Levine ${ }^{1}$, Maria V. Grau ${ }^{2}$, Øivind Midttun ${ }^{3}$, Per M. Ueland ${ }^{4}$, \\ Dennis J. Ahnen ${ }^{5}$, Elizabeth L. Barry ${ }^{2}$, Shirley Tsang ${ }^{6}$, David Munroe ${ }^{6}$, Iqbal Ali ${ }^{7}$, Robert W. \\ Haile $^{1}$, Robert S. Sandler ${ }^{8}$, and John A. Baron ${ }^{2}$ \\ 1 Department of Preventive Medicine, Keck School of Medicine, University of Southern California, Los \\ Angeles, $C A$ \\ 2Departments of Community and Family Medicine, Dartmouth Medical School, Hanover, NH \\ 3Bevital A/S, Armauer Hansens Hus, Bergen, Norway \\ 4Section for Pharmacology, Institute of Medicine, University of Bergen and Haukeland University Hospital, \\ Bergen, Norway \\ 5Department of Medicine, University of Colorado, Denver, CO \\ 6Laboratory of Molecular Technology, SAIC-Frederick, Inc., Frederick, MD \\ 7Division of Cancer Prevention, National Cancer Institute, Bethesda MD \\ 8Division of Gastroenterology and Hepatology, University of North Carolina, Chapel Hill, NC
}

\section{Abstract}

Background-Folate, other vitamin B cofactors, and genes involved in folate-mediated one-carbon metabolism (FOCM) all may play important roles in colorectal neoplasia. In this study, we examined the associations between dietary and circulating plasma levels of vitamins $\mathrm{B}_{2}, \mathrm{~B}_{6}$ and $\mathrm{B}_{12}$ and risk colorectal adenomas.

Methods-The Aspirin/Folate Polyp Prevention Study is a randomized clinical trial of folic acid supplementation and incidence of new colorectal adenomas in individuals with a history of adenomas $(\mathrm{n}=1,084)$. Diet and supplement use were ascertained through a food-frequency questionnaire administered at baseline. Blood collected at baseline was used to determine plasma B-vitamin levels. We used generalized linear regression to estimate risk ratios (RR) and 95\% confidence limits (CI) as measures of association.

\begin{abstract}
Results-We found a borderline significant inverse association with plasma $\mathrm{B}_{6}$ (pyridoxal 5' phosphate, PLP) and adenoma risk (adjusted RR Q4 vs. Q1 $=0.78,95 \% \mathrm{CI}=0.61-1.00$, p-trend $=0.08$ ). This association was not modified by folic acid supplementation or plasma folate. However, the protective association of PLP with adenoma risk was observed only among subjects who did not drink alcohol (p-interaction $=0.03$ ). Plasma $\mathrm{B}_{2}$ (riboflavin) was inversely associated with risk of advanced lesions (adjusted RR Q4 vs. Q1=0.51; 95\% CI=0.26-0.99, p-trend=0.12). No significant associations were observed between adenoma risk and plasma vitamin $\mathrm{B}_{12}$ or dietary intake of vitamin $\mathrm{B}_{2}$ and $\mathrm{B}_{6}$. When we examined specific gene-B-vitamin interactions, we observed a possible interaction between MTHFR-C677T and plasma $\mathrm{B}_{2}$ on risk of all adenomas.
\end{abstract}

Corresponding Author: Jane C. Figueiredo, Ph.D. Department of Preventive Medicine, Keck School of Medicine, University of Southern California 1450 Biggy Street 1509B Los Angeles CA 90033 USA tel: 3234427752 fax: 3234427787 email: janefigu@ usc.edu. 
Conclusion-Our results suggest that high levels of PLP and $\mathrm{B}_{2}$ may protect against colorectal adenomas.

\section{Keywords}

B vitamins; colorectal adenomas; clinical trial; folate; polymorphisms

\section{Introduction}

Folates play potentially important roles in carcinogenesis because of their role as major carriers of the one-carbon groups needed for intracellular methylation reactions and nucleotide synthesis $(1,2)$. Folate-associated one-carbon metabolism (FOCM) depends on B-vitamin cofactors for many of the key reactions involved. Thus methylenetetrahydrofolate reductase (MTHFR) requires vitamin $\mathrm{B}_{2}$ (riboflavin), the reactions catalyzed by methionine synthase reductase (MTRR) and methionine synthase (MTR) require vitamin $\mathrm{B}_{12}$ (cyanocobalamin) and cystathionine- $\beta$-synthase (CBS) requires vitamin $\mathrm{B}_{6}$ (pyridoxine). However, understanding of the relationships between B-vitamins and risk of incident colorectal adenomas is limited.

The role of vitamins $B_{2}, B_{6}$, and $B_{12}$, particularly dietary intake, has been investigated in several studies of colorectal adenomas and cancer. In the majority of studies, intake of vitamin $\mathrm{B}_{2}$ (3-7) and vitamin $B_{12}(3,5,6,8-12)$ have been unassociated with colorectal adenoma or cancer risk. However, there is stronger evidence to support an inverse association between dietary vitamin $\mathrm{B}_{6}$ and risk of colorectal adenomas or cancer $(3,4,12-17)$. In addition, levels of the main active form of circulating $\mathrm{B}_{6}$, pyridoxal 5'phosphate (PLP), were found to be inversely associated with risk of colon cancer in the Nurses' Health Study (14).

Other studies have investigated whether selected polymorphisms in FOCM genes coding for enzymes that require B-vitamins as co-factors modify the relationship between dietary intake of the vitamins and risk of colorectal adenomas or cancer, but results have been inconsistent $(5,6,18-25)$. A few studies have also reported on the role of polymorphic FOCM genes on risk of adenomas in individuals with a previous history of adenomas $(26,27)$, but have not yet explored the inter-relationships between these polymorphisms and intake or blood levels of Bvitamins.

In this randomized clinical trial of aspirin use and folic acid supplementation, we examined the associations of baseline plasma levels and dietary intake of vitamins $\mathrm{B}_{2}, \mathrm{~B}_{6}$ and $\mathrm{B}_{12}$ with risk of colorectal adenoma occurrence. We also assessed whether any B-vitamin association with adenoma risk was modified by folic acid supplementation, baseline plasma folate, multivitamin use, alcohol use, smoking, age or polymorphisms in key FOCM genes, methylenetetrahydrofolate reductase (MTHFR), methionine synthase reductase (MTRR), methionine synthase (MTR) and cystathionine- $\beta$-synthase (CBS).

\section{Methods}

\section{Study Design}

The Aspirin/Folate Polyp Prevention Study is a randomized, double-blind, placebo-controlled trial of the efficacy of oral aspirin, folic acid, or both to prevent colorectal adenomas in patients with a history of adenomas (28). Recruitment began in July 6, 1994 and ended in March 20, 1998. The study was originally designed to investigate the chemopreventive potential of aspirin. Shortly after enrollment began (after 100 subjects had been randomized), the study was extended to incorporate folic acid supplementation in a three-by-two factorial design, with $1 \mathrm{mg}$ of folic acid or placebo incorporated into each aspirin treatment arm. The study protocol was approved by the Institutional Review Board at all 9 clinical centers and written informed 
consent was obtained from all study participants. The findings regarding aspirin and folic acid have been reported $(28,29)$.

\section{Study Population: Randomization, Interventions and Follow-Up}

Eligible individuals had at least one of the following: one or more histologically confirmed adenomas removed within 3 months before recruitment, one or more histologically confirmed adenomas removed within 16 months before recruitment and a lifetime history of two or more confirmed adenomas, or a histologically confirmed adenoma at least $1 \mathrm{~cm}$ in diameter removed within 16 months before recruitment. All participants were required to have had a complete colonoscopy documenting an absence of lesions remaining in the large bowel within three months of study entry and anticipated colonoscopy follow-up three years later. After completion of a 3-month aspirin run-in period, compliant individuals who wished to continue participating were randomized in a 1:1 ratio to $1 \mathrm{mg}$ per day of folic acid or placebo within strata defined by clinical center, sex and age (60 years or younger vs. older than 60 years). Initially three years of treatment and follow-up was planned. However, because of concern that a longer exposure to folic acid might be required to observe an anti-neoplastic effect (30), participants were asked to continue on the study treatment for a subsequent (second) colonoscopic surveillance cycle (usually 3 or 5 years). The present analysis includes 1,084 individuals who completed the first follow-up colonoscopy at least one year after randomization. When a surveillance colonoscopy was not performed at the end of the first follow-up interval, we used the last examination at least one year after randomization, on or before September 28, 2001 was used to demarcate the end of the follow-up period.

\section{Data Collection}

Questionnaires-All participants completed a questionnaire regarding personal characteristics, medical history and lifestyle habits. Dietary information was collected using the Block food frequency questionnaire administered to participants at baseline. The validity and reliability of the food frequency questionnaire has been described previously (31). Questions assessed the average consumption of a food item during the past year. Daily dietary nutrient intakes were calculated by multiplying frequency responses by the nutrient contents of the specified portion sizes using a comprehensive database. Brand and type of multivitamin supplement use were collected. Individuals who regularly consumed multivitamins (at least once per week) were considered to be "multivitamin users". Total daily alcohol intake was calculated as the sum of alcohol content from beer, wine and liquor.

Measurement of Baseline B-Vitamin Levels-Vitamin B assays were conducted at University of Bergen, Bergen, Norway. Blood samples were collected from non-fasting participants into 7-ml Vacutainer brand tubes containing EDTA at baseline. After collection, specimens were immediately put on ice and then centrifuged at $1100 \mathrm{~g}$ for 10 minutes. Whole blood, plasma and buffy coat fractions were stored at $-20^{\circ} \mathrm{C}$ and then transferred to Dartmouth Medical School where they were stored at $-80^{\circ} \mathrm{C}$ until analysis.

Vitamin $\mathrm{B}_{2}$ (riboflavin) and $\mathrm{B}_{6}$ (pyridoxal 5'phosphate, PLP, the main active form of vitamin $\mathrm{B}_{6}$ and pyridoxal, $\mathrm{PL}$ ) were determined in plasma by liquid chromatography-tandem mass spectrometry and vitamin $\mathrm{B}_{12}$ by microbiological assay using published methods $(32,33)$.

Genotyping Assays-The following polymorphisms were considered in this study: CBS-1080 C >T, A360A (rs1801181) and CBS-699 C >T, Y233Y (rs234706), MTHFR-677 C > T, V222A (rs1801133) and -1298 C>T, A429E (rs1801131), MTR-2756 A>G, D919G (rs1805087) and MTRR-66 A>G, I22M (rs1801394). These polymorphisms, selected on the basis of previous studies suggesting possible biological functions, were genotyped using the 5'nuclease TaqMan allelic discrimination assay on the ABI 7900HT (Applied Biosystems, 
Foster City, CA). All oligo primers and dual-labeled allele discrimination probes were designed and developed either using Assay-by Design (Applied Biosystem Inc, Foster City, CA) or the Primer Express software 2.0 (Applied Biosystem). Each assay contained quality control DNAs of the homozygous wild-type, heterozygous, and homozygous variant alleles for the respective polymorphisms in addition to the no-target controls. Laboratory staff was blinded to outcome status. Call rates for each polymorphism were $>98 \%$. Specific experimental details are available upon request from the authors.

Study Outcomes-Adenoma occurrence was determined by colonoscopy and pathology review. All important medical events reported by participants were verified with medical record review. Records for all large bowel procedures (endoscopy or surgery) were obtained,and slides for all tissue removed from the bowel were retrieved and sent to a single study pathologist for uniform review. Lesions were classified as neoplastic (adenomatous, including sessile serrated adenomas) or nonneoplastic.

The primary study outcome was the occurrence of one or more colorectal adenomas detected at least one year following randomization up to the end of the first follow-up period. A secondary outcome was the occurrence of one or more advanced lesions, defined as invasive carcinoma or adenomas with at least $25 \%$ villous component, high grade dysplasia, or estimated size of 1 centimeter or greater.

\section{Statistical Methods}

Fisher's exact and Student's $t$ tests were used to compare individuals who had an adenoma occurrence and those that did not with regard to categorical and continuous variables, respectively. Spearman's rank correlation coefficient was used to calculate the correlation between plasma and dietary vitamin-B levels. Baseline plasma quartile $(\mathrm{Q})$ levels of vitamins $\mathrm{B}_{2}, \mathrm{~B}_{6}$ and $\mathrm{B}_{12}$ and dietary quartiles levels for vitamins $\mathrm{B}_{2}$ and $\mathrm{B}_{6}$ were the main exposures of interest. We did not examine dietary vitamin $B_{12}$ use because it was not estimated by the food frequency questionnaire software. Overdispersed generalized linear models for the Poisson family as an approximation to the binomial family were used to compute crude and adjusted risk ratios to assess the risk of at least one new adenoma. Covariates included in the models were age, sex, center, duration of follow-up, aspirin treatment group, and baseline multivitamin use. We included multivitamin use in our final models as an indirect adjustment for other nutrients/vitamins and unknown lifestyle factors, although exclusion of this variable from adjusted models did not substantially change any of the results. We also report a fully-adjusted model including plasma levels or dietary intake of other B-vitamins (including folate). Further adjustment for BMI, smoking, alcohol use, family history of colorectal cancer, 25-OH vitamin D levels, dietary calcium intake, dietary methionine, and red meat consumption did not substantially change the estimated relative risk, and we report here the more parsimonious models. For plasma measures, we also adjusted for time from blood draw to measurement (years) to account for possible sample degradation, but this variable was not statistically significant in any of the regression models nor did the estimates of risk change substantially.

The possibility that baseline factors modified the B-vitamin effect was assessed in these models with the use of interaction terms and Wald tests (with or without adjustment for other variables). The following baseline factors were considered: folic acid supplement group (yes vs. no), plasma folate (above vs. below median), alcohol use (none vs. 1+ drink/day), smoking (never vs. ever), age (above vs. below median) and multivitamin use (none vs. regular use of at least once per week). We conducted stratified analysis to obtain stratum specific estimates of risk and $95 \% \mathrm{CI}$. We assessed the potential effect modification of these variables only for the risk of any adenoma occurrence because of small numbers of advanced lesions. 
We also tested whether there were statistically significant interactions between polymorphisms in folate genes and B-vitamin plasma/dietary levels on adenoma risk. We considered six polymorphisms in four key genes coding for enzymes that require vitamins $\mathrm{B}_{2}, \mathrm{~B}_{6}$ or $\mathrm{B}_{12}$ as co-factors: CBS-1080 C >T and -699 C > T, MTHFR-677 C >T and -1298 C > T, MTR-2756 A $>$ G and MTRR-66 A>G. We assessed Hardy-Weinberg equilibrium by using a contingency table chi-square test to compare observed genotype frequencies to those expected under HardyWeinberg equilibrium. For the majority of polymorphisms, we grouped the heterozygotes with the common homozygotes, in agreement with findings from previous studies, which suggest a recessive model for polymorphisms in MTHFR (34,35), MTRR (36) and CBS (37). For MTR-2756 A/G, we grouped the heterozygotes with the less common homozygote variants to accomodate limited numbers. For dietary intake of vitamins $\mathrm{B}_{2}$ and $\mathrm{B}_{6}$, we used the median to define subgroups when examining gene-vitamin B interactions.

All analyses of study folate treatment were conducted according to the principle of intention to treat. Two-sided p-values less then 0.05 were considered statistically significant. We did not adjust for multiple testing as per convention in epidemiological studies testing a priori defined hypotheses. Stata (version 9.2) was used for all analyses.

\section{Results}

\section{Characteristics of study participants}

Table 1 summarizes the characteristics of the study participants that completed a follow-up colonoscopy at least one year after randomization. Most were male $(n=690,64 \%)$ and the overall mean age was $57.4(\mathrm{SD}=9.6)$. Of the 1,084 subjects with endpoint data, $471(43.5 \%)$ were found to have one or more colorectal adenoma at least one year after randomization. Subjects with new adenomas did not differ significantly from those without in terms of baseline dietary and total folate, but were more likely to have lower baseline plasma folate levels $(\mathrm{p}=0.025)$ and consume more alcohol $(\mathrm{p}=0.006)$. The mean $(\mathrm{SD})$ time from randomization to completion of the first follow-up interval was 32.7 (3.6) months.

\section{Correlation between plasma B vitamins}

Plasma B-vitamins were significantly correlated with each other. Plasma $\mathrm{B}_{2}$ was modestly correlated with PLP (rho $=0.44), \mathrm{PL}(\mathrm{rho}=0.50), \mathrm{B}_{12}(\mathrm{rho}=0.30)$ and folate $(\mathrm{rho}=0.45)$. Plasma PLP and PL were strongly correlated (rho $=0.82$ ) and both were modestly correlated with plasma vitamin $\mathrm{B}_{12}$ (rho $=0.38$ and 0.34 , respectively) and folate (rho $=0.48$ and 0.53 , respectively). Similarly, plasma $\mathrm{B}_{12}$ and folate were modestly correlated (rho=0.34).

\section{Association of baseline B-vitamin plasma and dietary levels and adenoma risk}

Baseline PLP concentration was borderline inversely associated with risk of any adenoma (RR for $\mathrm{Q} 4$ vs. $\mathrm{Q} 1=0.78,95 \% \mathrm{CI}=0.61-1.00$, p-trend $=0.08$, Table 2 ). However, there was no association between PLP levels and risk of advanced lesions (RR for Q4 vs. Q1 $=0.89,95 \%$ $\mathrm{CI}=0.46-1.73$ ). Baseline PL levels were also inversely associated with all adenoma risk (RR for Q4 vs. Q1 $=0.78 ; 95 \% \mathrm{CI}=0.62-0.99)$, an association that was attenuated after further adjustment for plasma $\mathrm{B}_{2}, \mathrm{~B}_{12}$ and folate (RR for $\mathrm{Q} 4$ vs. $\mathrm{Q} 1=0.86$; $95 \% \mathrm{CI}=0.66-1.12$ ). For advanced lesions, the PL RR for Q4 vs. Q1 was 0.65 (95\% CI=0.32-1.32 in a fully adjusted model). Baseline dietary vitamin $\mathrm{B}_{6}$ intake was modestly correlated with plasma PLP and PL $($ rho $=0.17$ and 0.15 , respectively; $\mathrm{p}<0.001)$, but did not show any association with risk of any adenoma (RR for Q4 vs. Q1=1.05; 95\% CI=0.78-1.41) or advanced lesions (RR for Q4 vs. $\mathrm{Q} 1=0.99 ; 95 \% \mathrm{CI}=0.46-2.12$, Table 3 ). We were also able to examine total $\mathrm{B}_{6}$ intake (diet plus supplements), and observed non-significant associations similar to those for dietary $\mathrm{B}_{6}$ (data not shown). 
Baseline plasma vitamin $\mathrm{B}_{2}$ was not significantly associated with adenoma risk (adjusted RR for Q4 vs. Q1 $=0.95,95 \% \mathrm{CI}=0.75-1.20$ ) although there was a statistically significant inverse association for advanced lesions ( $\mathrm{RR}$ for $\mathrm{Q} 4$ vs. $\mathrm{Q} 1=0.51,95 \% \mathrm{CI}=0.26-0.99$, $\mathrm{p}$-trend=0.12, Table 2). Baseline dietary vitamin $B_{2}$ was modestly correlated with plasma levels (rho=0.1; $\mathrm{p}<0.001$ ), and showed a borderline non-significant inverse association with risk of all adenomas (RR for Q4 vs. Q1 $=0.83$; 95\% CI=0.64-1.08, Table 3), but not with advanced lesions ( $\mathrm{RR}$ for $\mathrm{Q} 4$ vs. Q1=0.78; 95\% CI=0.39-1.57, Table 3).

There was no significant association between baseline plasma $\mathrm{B}_{12}$ and risk of any adenoma (RR for Q4 vs. Q1=0.91, 95\% CI=0.73-1.15) or advanced lesions (RR for Q4 vs. Q1=0.94, 95\% CI=0.52-1.69, Table 2).

When we examined multivitamin use with adjustment for plasma vitamins $\mathrm{B}_{2}, \mathrm{~B}_{6}$ and $\mathrm{B}_{12}$ and folate, we observed no association with any adenoma (RR for Q4 vs. Q1=1.02; 95\%

$\mathrm{CI}=0.85-1.23)$ or advanced lesions $(\mathrm{RR}$ for $\mathrm{Q} 4$ vs. $\mathrm{Q} 1=1.07 ; 95 \% \mathrm{CI}=0.66-1.73)$.

\section{Effect modification of folic acid treatment group, baseline plasma folate, age, smoking, multivitamin and alcohol use at baseline}

Table 4 provides estimates of risk for any adenoma according to baseline plasma $\mathrm{B}_{2}, \mathrm{~B}_{6}$ and $\mathrm{B}_{12}$ stratified by folic acid treatment group, multivitamin use and alcohol use. There was no evidence that folic acid supplementation modified the association between any plasma B vitamin and adenoma risk (Table 4). In addition, baseline plasma folate levels did not modify the associations of plasma vitamin $B_{2}$ ( $p$-interaction $\left.=0.75\right), P L P(p-v a l u e$ for interaction $=0.69$ ), PL (p-value for interaction=0.68) or vitamin $\mathrm{B}_{12}(\mathrm{p}$-value for interaction=0.19) with adenoma risk (data not shown). Similarly, multivitamin use at baseline did not significantly modify the association between plasma $\mathrm{B}_{2}, \mathrm{~B}_{6}$ (PLP and PL) or $\mathrm{B}_{12}$ and adenoma risk. However, alcohol use did appear to interact significantly with the association of PLP and risk of all adenomas: the inverse association was evident only in non-drinkers ( $p$-value for interaction=0.03). No other significant interactions with PL or dietary $\mathrm{B}_{2}$ or $\mathrm{B}_{6}$ were observed. Smoking status and age did not significantly modify any of the associations with plasma or dietary intake of $\mathrm{B}_{2}$, $\mathrm{B}_{6}$ or $\mathrm{B}_{12}$ (all p-interactions $>0.05$ ).

\section{Selected gene-nutrient interactions and adenoma risk}

There was no evidence of deviation from Hardy-Weinberg equilibrium for any of the polymorphisms investigated. As previously reported by us, MTHFR -C677T and MTHFRC1298T were not significantly associated with adenoma risk in adjusted models (38). The relative risk for MTR-2756 A/G or G/G vs. A/A was 0.99 (95\% CI=0.85-1.15), for MTRR-66 $\mathrm{G} / \mathrm{G}$ vs. $\mathrm{A} / \mathrm{A}$ or $\mathrm{A} / \mathrm{G}$ it was 0.97 (95\% CI=0.83-1.14) and for CBS-699 T/T vs. $\mathrm{C} / \mathrm{C}$ or $\mathrm{C} / \mathrm{T}$ it was 0.80 (95\% CI=0.62-1.03). We observed a significantly increased risk for any adenoma recurrence among individuals with the CBS-1080 T/T genotype compared to those with at least one $\mathrm{C}$ allele ( $\mathrm{RR}=1.29,95 \% \mathrm{CI}=1.06-1.56)$.

There was a suggestive, but non-significant, interaction between the MTHFR- C677T polymorphism and baseline plasma vitamin $\mathrm{B}_{2}$ on risk of all adenomas (Table 5). Among subjects who were homozygotes for the (variant) $\mathrm{T}$ allele there was a non-significantly increased risk of adenomas associated with higher plasma vitamin $B_{2}$ (adjusted $R R=1.40 ; 95 \%$ $\mathrm{CI}=0.85-2.30$ ), while those who were heterozygotes or homozygotes for the common $677 \mathrm{C}$ allele showed a reduced risk (adjusted $\mathrm{RR}=0.87 ; 95 \% \mathrm{CI}=0.73-1.03$, $\mathrm{p}$-interaction $=0.07$ ). The association between baseline median dietary vitamin $\mathrm{B}_{2}$ levels and adenoma risk did not significantly differ by MTHFR-677C/T or $-1298 \mathrm{C} / \mathrm{T}$ genotypes (data not shown). 
There was no indication that the risk of adenomas associated with baseline plasma vitamin $\mathrm{B}_{12}$ differed by MTHFR-677C/T, MTR-2756A/G or MTRR-66A/G genotypes or that the association between baseline plasma vitamin $\mathrm{B}_{6}$ (PLP or PL (data not shown)) and adenoma risk differed by MTHFR-677C/T, CBS-1080C/T or -699C/T genotypes. Baseline dietary levels of vitamin $\mathrm{B}_{6}$ also showed no evidence of effect modification by these genotypes (data not shown).

\section{Discussion}

In this randomized clinical trial of aspirin use and folic acid supplementation, we found a borderline significant inverse association between baseline plasma vitamin $\mathrm{B}_{6}$ (PLP, the active form of $\mathrm{B}_{6}$ ) levels and risk of all adenomas, but not advanced lesions. The inverse association was not modified by folic acid supplementation or baseline plasma folate, although we did observe a significant interaction between plasma PLP levels and alcohol use. Dietary and total intake of $\mathrm{B}_{6}$ as well as plasma $\mathrm{B}_{12}$ were not associated with risk of adenomas or advanced lesions. Circulating levels of $B_{2}$ were inversely associated with risk of advanced lesions, while dietary intake showed a non-significant inverse trend for all adenomas. There were no significant interactions between polymorphic FOCM genes and their respective B vitamin cofactors, except possibly for MTHFR-C677T and plasma $\mathrm{B}_{2}$.

In FOCM, vitamin $\mathrm{B}_{6}$ acts as a co-factor for serine hydroxyl-methyltransferase (SHMT), which catalyzes the formation of glycine and 5,10-methylenetetrathydrofolate, a key carrier of one carbon groups in nucleotide synthesis and DNA repair. In addition, vitamin $\mathrm{B}_{6}$ is a co-factor for CBS, which catalyzes the irreversible conversion of homocysteine to cystathionine, reactions that may affect intracellular SAH levels in vivo (39). Vitamin $\mathrm{B}_{6}$ is also involved in nearly 100 enzymatic reactions (40) and has been shown to reduce oxidative stress as well as cell proliferation and angiogenesis $(41,42)$, all effects that could result in reduced risks of neoplasia. Vitamin $\mathrm{B}_{6}$ is found in poultry, fish, liver, whole grains, nuts and legumes, and deficiency has been associated with impaired FOCM (43) and chemically induced colon tumor formation in animal models (41).

In contrast to our results for plasma levels, we found no statistically significant association of baseline dietary vitamin $\mathrm{B}_{6}$ with adenoma occurrence. Other observational studies have reported an inverse relationship between dietary vitamin $\mathrm{B}_{6}$ intake and risk of colorectal adenomas $(3,4)$ and a more consistent association with cancer $(7,12-17)$. Our negative results could have been due to measurement error in the estimation of intake, which would tend to exert a conservative bias (44). We are aware of only one other study that examined plasma vitamin $\mathrm{B}_{6}(\mathrm{PLP})$ levels and colorectal adenoma and cancer risk. Wei and colleagues showed a significant inverse association for PLP and risk of colon cancer and a borderline significant risk of incident advanced distal colorectal adenomas among women (14).

Previous studies have investigated the possible interaction between polymorphisms in MTHFR and dietary intake of vitamin $\mathrm{B}_{6}$ on risk of colorectal cancer and adenomas. A stronger protective effect of vitamin $\mathrm{B}_{6}$ on adenoma risk has been observed among individuals with the MTHFR-677 T/T genotype compared to those with at least one $C$ allele $(6,20,21)$, though this interaction was statistically significant in only one study (6). There has been no previous investigation regarding interactions between plasma or dietary vitamin $\mathrm{B}_{6}$ and two functional polymorphisms in the $\mathrm{B}_{6}$-dependent CBS enzyme (i.e., CBS-699C/T and -1080C/T) (45) on risk of adenomas.

Vitamin $\mathrm{B}_{2}$ (found in dairy products, poultry, fish, grains and enriched food products) is the precursor for flavin mononucleotide and flavin adenine dinucleotide (FAD), key cofactors in multiple oxidation/reduction reactions including the reduction of 5,10-MTHF to 5-MTHF, 
catalyzed by MTHFR (46). Our data did not suggest a significant association between plasma riboflavin levels and risk of any adenoma, although we observed a borderline significant inverse association with risk of advanced lesions, and suggestive associations with dietary intake. Other studies have also reported non-significant associations of dietary vitamin $B_{2}$ with risk of colorectal adenomas (3-7). The only study to observe a significant protective effect of dietary $\mathrm{B}_{2}$ was a case-control study of colorectal adenomas in the Netherlands (8). Contrary to the Netherlands, foods in the U.S. have been enriched with vitamin $B_{2}$ since 1940s (47). Thus, our study population may have relatively high $\mathrm{B}_{2}$ intake (48), leaving us with insufficient variation in our population to observe significant associations.

We also investigated whether the MTHFR-677C/T polymorphism modified the relationship between plasma levels of vitamin $B_{2}$ and adenoma risk. The MTHFR- $677 \mathrm{~T}$ allele codes for a valine at position 222 in the FAD binding domain of the enzyme and the variant enzyme has relatively lower affinity for the FAD cofactor $(49,50)$ suggesting that a high level of the FAD cofactor may stabilize the variant enzyme just as folate does $(51,52)$. However, we observed a non-significant increase in adenoma risk for those with the MTHFR-677T/T genotype and plasma $\mathrm{B}_{2}$ levels above the median compared to those with that genotype and lower plasma $\mathrm{B}_{2}$ levels. There was a borderline significant association between plasma $\mathrm{B}_{2}$ and any adenoma occurrence among those with at least one $\mathrm{C}$ allele. These findings contrast with a report that dietary intake of $\mathrm{B}_{2}$ is inversely associated with adenoma risk in those with the MTHFR-677T/ T genotype (8). Other studies found no evidence of interaction between dietary vitamin $\mathrm{B}_{2}$ and MTHFR 677C $>$ T on risk of colorectal adenomas $(3,8)$ or cancer $(5)$. When we examined dietary vitamin $\mathrm{B}_{2}$ levels and adenoma risk there was no suggestion of effect modification by the MTHFR-677C/T genotype.

Vitamin $B_{12}$ is a co-factor of MTR, which, paired with MTRR, catalyzes transfer of methyl groups from 5-MTHF to homocysteine via vitamin $B_{12}$. Vitamin $B_{12}$ is found exclusively animal products, and deficiencies of either enzyme or the $\mathrm{B}_{12}$ cofactor essentially trap 5-MTHF molecules at the $\mathrm{B}_{12}$ transfer step (53). In agreement with our findings, the majority of studies for both adenoma $(3,8,11)$ and cancer risk $(5,6,10,12)$ have found no evidence of an association with dietary vitamin $B_{12}$. There has been considerable study of the role of polymorphisms in MTR-2756A $>\mathrm{G}$ and MTRR-66A $>\mathrm{G}$, including assessment of their interaction with vitamin $\mathrm{B}_{12}$ in colorectal neoplasia $(6,22,26,54-57)$. The MTRR-A66G variant allele has been associated with a lower affinity for MTR and possibly less efficient reducing capacity (58), while the MTR-A2756G polymorphism has been inconsistently reported to affect plasma homocysteine and folate levels $(59,60)$. Data regarding MTRR-G66 have been inconsistent in this regard $(5,6,26,61,62)$. As in our study, the MTR-2756A->G polymorphism does not appear to play a role in colorectal carcinogenesis $(22,54,57)$. Additionally our data are consistent with other studies $(6,20)$ that have found no evidence of interaction between MTHFR-677C-> T and $\mathrm{B}_{12}$.

In agreement with our findings, other investigations have not found that folate status modified the association of plasma or dietary vitamin B intakes with risk of colorectal neoplasia. The Nurses' Health Study did not find a statistically significant stronger protective effect of high PLP levels among individuals with low plasma folate, non-users of multivitamins or B-vitamin supplements on colorectal cancer or adenoma risk (14). At least one other study also failed to observe a significant interaction between intakes of vitamins $\mathrm{B}_{2}, \mathrm{~B}_{6}$ and $\mathrm{B}_{12}$ and dietary folate on risk of colorectal adenomas (3). These data may reflect limited statistical power to detect interaction, but may also suggest that PLP may protect against colorectal neoplasia through biological pathways other than FOCM. We observed a potential interaction between PLP and alcohol. Alcohol is a known folate "antagonist" that affects dietary methyl supply. In addition to effects on folate availability, alcohol is metabolized into acetaldehyde, which has been shown to be carcinogenic in the colorectum possibly through inhibition of DNA methylation 
and interactions with retinoid metabolism (63). Findings from two other studies $(12,13)$ observed a protective effect of vitamin $\mathrm{B}_{6}$ among heavy drinkers, and further study is need to better understand these relationships.

This study has several limitations. The generalizability of our results may be limited as all participants in this clinical trial were volunteers who had a previous history of at least one colorectal adenoma and so represent a restricted part of the colon cancer risk spectrum. We had a limited sample size to investigate risk of advanced lesions, a clinically important endpoint. We used a validated semi-quantitative food frequency questionnaire, but these are still subject to measurement error, which may introduce substantial biases, generally conservative (44). Also, we did not consider all polymorphisms in CBS, MTR, MTRR and MTHFR, and we do not have any information on other key polymorphic FOCM genes. For example, serine hydroxymethyltransferase (SHMT) is a vitamin B $_{6}$ dependent enzyme involved in purine and pyrimidine nucleotide synthesis, and previous investigation has suggested a potential interaction between the SHMT-1420C $>$ T polymorphism and dietary levels of vitamin $B_{6}$ in colorectal adenoma risk (19).

Strengths of this study include the measurement of baseline plasma vitamin B levels (though in non-fasting bloods), genotypes in key FOCM genes and the large sample size. Because of the prospective design, recall or selection biases are unlikely to explain our findings in this study. In addition, inclusion only of individuals with a clean colonoscopy in this prospective clinical trial allowed us to assess the effect of B-vitamins on incident rather than prevalent adenomas, and thereby to make clear the temporal relationships between intake and adenoma occurrence. Furthermore, the high follow-up rates in this study (29) minimizes the concern that differential rates of follow-up affected our results.

In summary, our results suggest that high baseline levels of PLP and $\mathrm{B}_{2}$ may protect against new colorectal adenomas among individuals with a previous history of adenomas.

\section{Acknowledgements}

This work was supported in part by grants (R01-CA-059005, and U54-CA-100971) from the National Institutes of Health. J.C.F. is supported in part by a post-PhD Research Fellowship from the National Cancer Institute of Canada (\#017602). We thank all the individuals who participated in this clinical trial.

Funding

This work was supported in part by funding (R01-CA-059005, U54-CA-100971) from the National Cancer Institute, National Institutes of Health.

\section{Abbreviations}

CI, confidence interval; CBS, cystathionine- $\beta$-synthase; FOCM, folate-mediated one-carbon metabolism; MTHFR, methylenetetrahydrofolate reductase; MTR, methionine synthase;

MTRR, methionine synthase reductase; PLP, pyridoxal 5'phosphate; RR, rate ratio.

\section{References}

1. Kim YI. Role of folate in colon cancer development and progression. J Nutr 2003;133(11 Suppl 1): 3731S-3739S. [PubMed: 14608107]

2. Giovannucci E. Epidemiologic studies of folate and colorectal neoplasia: a review. J Nutr 2002;132(8 Suppl):2350S-2355S. [PubMed: 12163691]

3. Boyapati SM, Bostick RM, McGlynn KA, et al. Folate intake, MTHFR C677T polymorphism, alcohol consumption, and risk for sporadic colorectal adenoma (United States). Cancer Causes Control 2004;15(5):493-501. [PubMed: 15286469] 
4. Benito E, Cabeza E, Moreno V, Obrador A, Bosch FX. Diet and colorectal adenomas: a case-control study in Majorca. Int J Cancer 1993;55(2):213-9. [PubMed: 8370618]

5. Otani T, Iwasaki M, Hanaoka T, et al. Folate, vitamin B6, vitamin B12, and vitamin B2 intake, genetic polymorphisms of related enzymes, and risk of colorectal cancer in a hospital-based case-control study in Japan. Nutr Cancer 2005;53(1):42-50. [PubMed: 16351505]

6. Le Marchand L, Donlon T, Hankin JH, Kolonel LN, Wilkens LR, Seifried A. B-vitamin intake, metabolic genes, and colorectal cancer risk (United States). Cancer Causes Control 2002;13(3):23948. [PubMed: 12020105]

7. La Vecchia C, Braga C, Negri E, et al. Intake of selected micronutrients and risk of colorectal cancer. Int J Cancer 1997;73(4):525-30. [PubMed: 9389567]

8. van den Donk M, Buijsse B, van den Berg SW, et al. Dietary intake of folate and riboflavin, MTHFR C677T genotype, and colorectal adenoma risk: a Dutch case-control study. Cancer Epidemiol Biomarkers Prev 2005;14(6):1562-6. [PubMed: 15941973]

9. Harnack L, Jacobs DR Jr. Nicodemus K, Lazovich D, Anderson K, Folsom AR. Relationship of folate, vitamin B-6, vitamin B-12, and methionine intake to incidence of colorectal cancers. Nutr Cancer 2002;43(2):152-8. [PubMed: 12588695]

10. Slattery ML, Schaffer D, Edwards SL, Ma KN, Potter JD. Are dietary factors involved in DNA methylation associated with colon cancer? Nutr Cancer 1997;28(1):52-62. [PubMed: 9200151]

11. Pufulete M, Al-Ghnaniem R, Leather AJ, et al. Folate status, genomic DNA hypomethylation, and risk of colorectal adenoma and cancer: a case control study. Gastroenterology 2003;124(5):1240-8. [PubMed: 12730865]

12. Ishihara J, Otani T, Inoue M, Iwasaki M, Sasazuki S, Tsugane S. Low intake of vitamin B-6 is associated with increased risk of colorectal cancer in Japanese men. J Nutr 2007;137(7):1808-14. [PubMed: 17585035]

13. Larsson SC, Giovannucci E, Wolk A. Vitamin B6 intake, alcohol consumption, and colorectal cancer: a longitudinal population-based cohort of women. Gastroenterology 2005;128(7):1830-7. [PubMed: 15940618]

14. Wei EK, Giovannucci E, Selhub J, Fuchs CS, Hankinson SE, Ma J. Plasma vitamin B6 and the risk of colorectal cancer and adenoma in women. J Natl Cancer Inst 2005;97(9):684-92. [PubMed: 15870439]

15. Jansen MC, Bueno-de-Mesquita HB, Buzina R, et al. Dietary fiber and plant foods in relation to colorectal cancer mortality: the Seven Countries Study. Int J Cancer 1999;81(2):174-9. [PubMed: 10188715]

16. Kune G, Watson L. Colorectal cancer protective effects and the dietary micronutrients folate, methionine, vitamins B6, B12, C, E, selenium, and lycopene. Nutr Cancer 2006;56(1):11-21. [PubMed: 17176213]

17. Theodoratou E, Farrington SM, Tenesa A, et al. Dietary vitamin b6 intake and the risk of colorectal cancer. Cancer Epidemiol Biomarkers Prev 2008;17(1):171-82. [PubMed: 18199722]

18. Moat SJ, Ashfield-Watt PA, Powers HJ, Newcombe RG, McDowell IF. Effect of riboflavin status on the homocysteine-lowering effect of folate in relation to the MTHFR (C677T) genotype. Clin Chem 2003;49(2):295-302. [PubMed: 12560354]

19. van den Donk M, Visker MH, Harryvan JL, Kok FJ, Kampman E. Dietary intake of B-vitamins, polymorphisms in thymidylate synthase and serine hydroxymethyltransferase 1, and colorectal adenoma risk: a Dutch case-control study. Cancer Lett 2007;250(1):146-53. [PubMed: 17113224]

20. Ulrich CM, Kampman E, Bigler J, et al. Colorectal adenomas and the C677T MTHFR polymorphism: evidence for gene-environment interaction? Cancer Epidemiol Biomarkers Prev 1999;8(8):659-68. [PubMed: 10744125]

21. Slattery ML, Potter JD, Samowitz W, Schaffer D, Leppert M. Methylenetetrahydrofolate reductase, diet, and risk of colon cancer. Cancer Epidemiol Biomarkers Prev 1999;8(6):513-8. [PubMed: 10385141]

22. Goode EL, Potter JD, Bigler J, Ulrich CM. Methionine synthase D919G polymorphism, folate metabolism, and colorectal adenoma risk. Cancer Epidemiol Biomarkers Prev 2004;13(1):157-62. [PubMed: 14744749] 
23. Ulrich CM, Bigler J, Bostick R, Fosdick L, Potter JD. Thymidylate synthase promoter polymorphism, interaction with folate intake, and risk of colorectal adenomas. Cancer Res 2002;62(12):3361-4. [PubMed: 12067974]

24. Ma J, Stampfer MJ, Giovannucci E, et al. Methylenetetrahydrofolate reductase polymorphism, dietary interactions, and risk of colorectal cancer. Cancer Res 1997;57(6):1098-102. [PubMed: 9067278]

25. Levine AJ, Siegmund KD, Ervin CM, et al. The methylenetetrahydrofolate reductase 677C-->T polymorphism and distal colorectal adenoma risk. Cancer Epidemiol Biomarkers Prev 2000;9(7): 657-63. [PubMed: 10919734]

26. Hubner RA, Muir KR, Liu JF, et al. Folate metabolism polymorphisms influence risk of colorectal adenoma recurrence. Cancer Epidemiol Biomarkers Prev 2006;15(9):1607-13. [PubMed: 16985020]

27. Martinez ME, Thompson P, Jacobs ET, et al. Dietary factors and biomarkers involved in the methylenetetrahydrofolate reductase genotype-colorectal adenoma pathway. Gastroenterology 2006;131(6):1706-16. [PubMed: 17087956]

28. Baron JA, Cole BF, Sandler RS, et al. A randomized trial of aspirin to prevent colorectal adenomas. N Engl J Med 2003;348(10):891-9. [PubMed: 12621133]

29. Cole BF, Baron JA, Sandler RS, et al. Folic acid for the prevention of colorectal adenomas: a randomized clinical trial. Jama 2007;297(21):2351-9. [PubMed: 17551129]

30. Giovannucci E, Stampfer MJ, Colditz GA, et al. Multivitamin use, folate, and colon cancer in women in the Nurses' Health Study. Ann Intern Med 1998;129(7):517-24. [PubMed: 9758570]

31. http://www.nutritionquest.com/research/validation_study_ref.htm.

32. Midttun O, Hustad S, Solheim E, Schneede J, Ueland PM. Multianalyte quantification of vitamin B6 and $\mathrm{B} 2$ species in the nanomolar range in human plasma by liquid chromatography-tandem mass spectrometry. Clin Chem 2005;51(7):1206-16. [PubMed: 15976101]

33. Molloy AM, Scott JM. Microbiological assay for serum, plasma, and red cell folate using cryopreserved, microtiter plate method. Methods Enzymol 1997;281:43-53. [PubMed: 9250965]

34. Kono S, Chen K. Genetic polymorphisms of methylenetetrahydrofolate reductase and colorectal cancer and adenoma. Cancer Sci 2005;96(9):535-42. [PubMed: 16128738]

35. Sharp L, Little J. Polymorphisms in genes involved in folate metabolism and colorectal neoplasia: a HuGE review. Am J Epidemiol 2004;159(5):423-43. [PubMed: 14977639]

36. Wilson A, Platt R, Wu Q, et al. A common variant in methionine synthase reductase combined with low cobalamin (vitamin B12) increases risk for spina bifida. Mol Genet Metab 1999;67(4):317-23. [PubMed: 10444342]

37. Kruger WD, Evans AA, Wang L, et al. Polymorphisms in the CBS gene associated with decreased risk of coronary artery disease and increased responsiveness to total homocysteine lowering by folic acid. Mol Genet Metab 2000;70(1):53-60. [PubMed: 10833331]

38. Levine AJ, Wallace K, Tsang S, et al. MTHFR genotype and colorectal adenoma recurrence: data from a double blind placebo controlled clinical trial. Cancer Epidemiol Biomarkers Prev. in press

39. Yi P, Melnyk S, Pogribna M, Pogribny IP, Hine RJ, James SJ. Increase in plasma homocysteine associated with parallel increases in plasma S-adenosylhomocysteine and lymphocyte DNA hypomethylation. J Biol Chem 2000;275(38):29318-23. [PubMed: 10884384]

40. Komatsu S, Yanaka N, Matsubara K, Kato N. Antitumor effect of vitamin B6 and its mechanisms. Biochim Biophys Acta 2003;1647(12):127-30. [PubMed: 12686121]

41. Matsubara K, Komatsu S, Oka T, Kato N. Vitamin B6-mediated suppression of colon tumorigenesis, cell proliferation, and angiogenesis (review). J Nutr Biochem 2003;14(5):246-50. [PubMed: 12832027]

42. Matsubara K, Matsumoto H, Mizushina Y, Lee JS, Kato N. Inhibitory effect of pyridoxal 5'-phosphate on endothelial cell proliferation, replicative DNA polymerase and DNA topoisomerase. Int J Mol Med 2003;12(1):51-5. [PubMed: 12792808]

43. Martinez M, Cuskelly GJ, Williamson J, Toth JP, Gregory JF 3rd. Vitamin B-6 deficiency in rats reduces hepatic serine hydroxymethyltransferase and cystathionine beta-synthase activities and rates of in vivo protein turnover, homocysteine remethylation and transsulfuration. J Nutr 2000;130(5): 1115-23. [PubMed: 10801907]

44. Liu K. Measurement error and its impact on partial correlation and multiple linear regression analyses. Am J Epidemiol 1988;127(4):864-74. [PubMed: 3354551] 
45. Aras O, Hanson NQ, Yang F, Tsai MY. Influence of 699C-->T and 1080C-->T polymorphisms of the cystathionine beta-synthase gene on plasma homocysteine levels. Clin Genet 2000;58(6):455-9. [PubMed: 11149614]

46. McNulty H, McKinley MC, Wilson B, et al. Impaired functioning of thermolabile methylenetetrahydrofolate reductase is dependent on riboflavin status: implications for riboflavin requirements. Am J Clin Nutr 2002;76(2):436-41. [PubMed: 12145019]

47. Backstrand JR. The history and future of food fortification in the United States: a public health perspective. Nutr Rev 2002;60(1):15-26. [PubMed: 11842999]

48. Alaimo K, McDowell MA, Briefel RR, et al. Dietary intake of vitamins, minerals, and fiber of persons ages 2 months and over in the United States: Third National Health and Nutrition Examination Survey, Phase 1, 1988-91. Adv Data 1994;(258):1-28.

49. Guenther BD, Sheppard CA, Tran P, Rozen R, Matthews RG, Ludwig ML. The structure and properties of methylenetetrahydrofolate reductase from Escherichia coli suggest how folate ameliorates human hyperhomocysteinemia. Nat Struct Biol 1999;6(4):359-65. [PubMed: 10201405]

50. Yamada K, Chen Z, Rozen R, Matthews RG. Effects of common polymorphisms on the properties of recombinant human methylenetetrahydrofolate reductase. Proc Natl Acad Sci U S A 2001;98(26): 14853-8. [PubMed: 11742092]

51. Jacques PF, Kalmbach R, Bagley PJ, et al. The relationship between riboflavin and plasma total homocysteine in the Framingham Offspring cohort is influenced by folate status and the C677T transition in the methylenetetrahydrofolate reductase gene. J Nutr 2002;132(2):283-8. [PubMed: 11823591]

52. McNulty H, Dowey le RC, Strain JJ, et al. Riboflavin lowers homocysteine in individuals homozygous for the MTHFR 677C->T polymorphism. Circulation 2006;113(1):74-80. [PubMed: 16380544]

53. Banerjee RV, Matthews RG. Cobalamin-dependent methionine synthase. Faseb J 1990;4(5):1450 9. [PubMed: 2407589]

54. Ulrich CM, Curtin K, Potter JD, Bigler J, Caan B, Slattery ML. Polymorphisms in the reduced folate carrier, thymidylate synthase, or methionine synthase and risk of colon cancer. Cancer Epidemiol Biomarkers Prev 2005;14(11 Pt 1):2509-16. [PubMed: 16284371]

55. Ulvik A, Vollset SE, Hansen S, Gislefoss R, Jellum E, Ueland PM. Colorectal cancer and the methylenetetrahydrofolate reductase $677 \mathrm{C} \rightarrow \mathrm{T}$ and methionine synthase $2756 \mathrm{~A}->\mathrm{G}$ polymorphisms: a study of 2,168 case-control pairs from the JANUS cohort. Cancer Epidemiol Biomarkers Prev 2004;13(12):2175-80. [PubMed: 15598777]

56. Matsuo K, Ito H, Wakai K, et al. One-carbon metabolism related gene polymorphisms interact with alcohol drinking to influence the risk of colorectal cancer in Japan. Carcinogenesis 2005;26(12): 2164-71. [PubMed: 16051637]

57. Ma J, Stampfer MJ, Christensen B, et al. A polymorphism of the methionine synthase gene: association with plasma folate, vitamin B12, homocyst(e)ine, and colorectal cancer risk. Cancer Epidemiol Biomarkers Prev 1999;8(9):825-9. [PubMed: 10498402]

58. Olteanu H, Munson T, Banerjee R. Differences in the efficiency of reductive activation of methionine synthase and exogenous electron acceptors between the common polymorphic variants of human methionine synthase reductase. Biochemistry 2002;41(45):13378-85. [PubMed: 12416982]

59. Chen J, Stampfer MJ, Ma J, et al. Influence of a methionine synthase (D919G) polymorphism on plasma homocysteine and folate levels and relation to risk of myocardial infarction. Atherosclerosis 2001;154(3):667-72. [PubMed: 11257268]

60. Jacques PF, Bostom AG, Selhub J, et al. Effects of polymorphisms of methionine synthase and methionine synthase reductase on total plasma homocysteine in the NHLBI Family Heart Study. Atherosclerosis 2003;166(1):49-55. [PubMed: 12482550]

61. Matsuo K, Hamajima N, Hirai T, et al. Methionine Synthase Reductase Gene A66G Polymorphism is Associated with Risk of Colorectal Cancer. Asian Pac J Cancer Prev 2002;3(4):353-359. [PubMed: 12716294]

62. Hazra A, Wu K, Kraft P, Fuchs CS, Giovannucci EL, Hunter DJ. Twenty- four non-synonymous polymorphisms in the one-carbon metabolic pathway and risk of colorectal adenoma in the Nurses' Health Study. Carcinogenesis 2007;28(7):1510-9. [PubMed: 17389618] 
63. Seitz HK, Stickel F. Molecular mechanisms of alcohol-mediated carcinogenesis. Nat Rev Cancer 2007;7(8):599-612. [PubMed: 17646865] 
Table 1

Characteristics of individuals in the Polyp Prevention Trial of Aspirin and Folate who completed first year follow-up

\begin{tabular}{|c|c|c|c|}
\hline Characteristic & Adenoma occurrence & No adenoma occurrence & p-value \\
\hline No. of participants & 471 & \begin{tabular}{l|l}
613 & \\
\end{tabular} & \\
\hline Age at baseline, mean $\pm \mathrm{SD}(\mathrm{y})$ & $59.0 \pm 9.3$ & $56.2 \pm 9.6$ & $<0.001^{\#}$ \\
\hline Male Sex, No. (\%) & $321(68.2 \%)$ & $369(60.2 \%)$ & 0.007 \\
\hline Bodv-mass index $>30 \mathrm{~kg} / \mathrm{m}^{2}$, No. $(\%)$ & $117(24.9 \%)$ & $125(20.4 \%)$ & 0.080 \\
\hline Current cigarette smoker, No. (\%) & $86(18.5 \%)$ & $72(11.8 \%)$ & 0.002 \\
\hline Colorectal cancer in first-degree relative, No. (\%) & $143(37.1 \%)$ & $189(37.4 \%)$ & 0.949 \\
\hline Self identified as White, No. (\%) & $412(87.5 \%)$ & $516(84.2 \%)$ & 0.125 \\
\hline Aspirin use at baseline, No. (\%) & $291(61.8 \%)$ & $358(58.5 \%)$ & 0.274 \\
\hline Aspirin Treatment Group ${ }^{\nexists}$, No. $(\%)$ & $300(63.7 \%)$ & $421(68.7 \%)$ & 0.085 \\
\hline Folate Treatment Group, No. (\%) & $221(51.8 \%)$ & $280(50.0 \%)$ & 0.584 \\
\hline Baseline plasma folate, mean $\pm \mathrm{SD}(\mathrm{nmol} / \mathrm{L})$ & $21.9(15.3 \%)$ & $24.4(19.1 \%)$ & $0.025^{\#}$ \\
\hline Baseline plasma $\mathrm{B}_{2}$, mean $\pm \mathrm{SD}$ & $30.6 \pm 56.8$ & $27.7 \pm 43.6$ & $0.374^{\#}$ \\
\hline Baseline plasma $\mathrm{B}_{6}$, mean $\pm \mathrm{SD}$ & $76.3 \pm 89.2$ & $81.3 \pm 86.8$ & $0.378^{\#}$ \\
\hline Baseline plasma $\mathrm{B}_{12}$, mean $\pm \mathrm{SD}$ & $317.1 \pm 141.3$ & $333.7 \pm 177.1$ & $0.112^{\#}$ \\
\hline Multivitamin use, No. (\%) & $153(32.6 \%)$ & $226(37.1 \%)$ & 0.125 \\
\hline \multicolumn{4}{|l|}{ Dietary intake } \\
\hline Dietary folate intake, mean $\pm \mathrm{SD}(\mathrm{mg} / \mathrm{day})$ & $317.9 \pm 150.4$ & $320.7 \pm 162.4$ & $0.772^{\#}$ \\
\hline Total folate ${ }^{*}$, mean $\pm \mathrm{SD}(\mathrm{mg} / \mathrm{day})$ & $460.2 \pm 309.5$ & $461.9 \pm 284.7$ & $0.927^{\#}$ \\
\hline Dietary vitamin $\mathrm{B}_{2}^{\dagger}$, mean $\pm \mathrm{SD}((\mathrm{mg} /$ day $)$ & $30.6 \pm 56.8$ & $27.7 \pm 43.6$ & $0.729^{\#}$ \\
\hline Total vitamin $\mathrm{B}_{6}{ }^{*}$, mean $\pm \mathrm{SD}(\mathrm{mg} /$ day $)$ & $2.6 \pm 2.2$ & $2.5 \pm 2.0$ & $0.718^{\#}$ \\
\hline Total vitamin $\mathrm{B}_{12}{ }^{+}$, mean $\pm \mathrm{SD}(\mathrm{mg} /$ day $)$ & $2.6 \pm 5.8$ & $2.5 \pm 4.6$ & $0.779^{\#}$ \\
\hline \multicolumn{4}{|l|}{ Alcohol (drinks per day), No (\%) } \\
\hline None & $121(26.8 \%)$ & $206(35.4 \%)$ & \multirow[t]{3}{*}{0.006} \\
\hline 1 or less & $223(49.4 \%)$ & $271(46.6 \%)$ & \\
\hline 2 or more & $107(23.7 \%)$ & $105(18.0 \%)$ & \\
\hline \multicolumn{4}{|l|}{ Adenoma Characteristics (at baseline) ${ }^{\S}$} \\
\hline Number $($ mean \pm SD) & $1.7 \pm 1.1$ & $1.5 \pm 0.9$ & $<0.001^{\#}$ \\
\hline Large Adenomas $(>1 \mathrm{~cm})$, No. $(\%)$ & $107(22.7 \%)$ & $140(22.8 \%)$ & 0.962 \\
\hline Villous histology, No. (\%) & $60(12.7 \%)$ & $93(15.2 \%)$ & 0.254 \\
\hline Proximal location, No. (\%) & $248(52.7 \%)$ & $244(39.8 \%)$ & $<0.001$ \\
\hline \multicolumn{4}{|l|}{$F_{81}$ and $325 \mathrm{mg} /$ day aspirin treatment groups combined } \\
\hline \multicolumn{4}{|l|}{${ }^{*}$ Total folate and total $\mathrm{B} 6=$ dietary + supplements } \\
\hline \multicolumn{4}{|l|}{${ }^{\dagger}$ Total B2 from dietary sources only } \\
\hline \multicolumn{4}{|l|}{${ }_{\text {Total }} \mathrm{B}_{12}$ from supplements only } \\
\hline \multicolumn{4}{|c|}{$\S_{\text {using standard definitions by Polyp Prevention Study Group }(28,29)}$} \\
\hline \multicolumn{4}{|l|}{ *** ${ }^{*}$ chi-square test } \\
\hline \# & & & \\
\hline
\end{tabular}




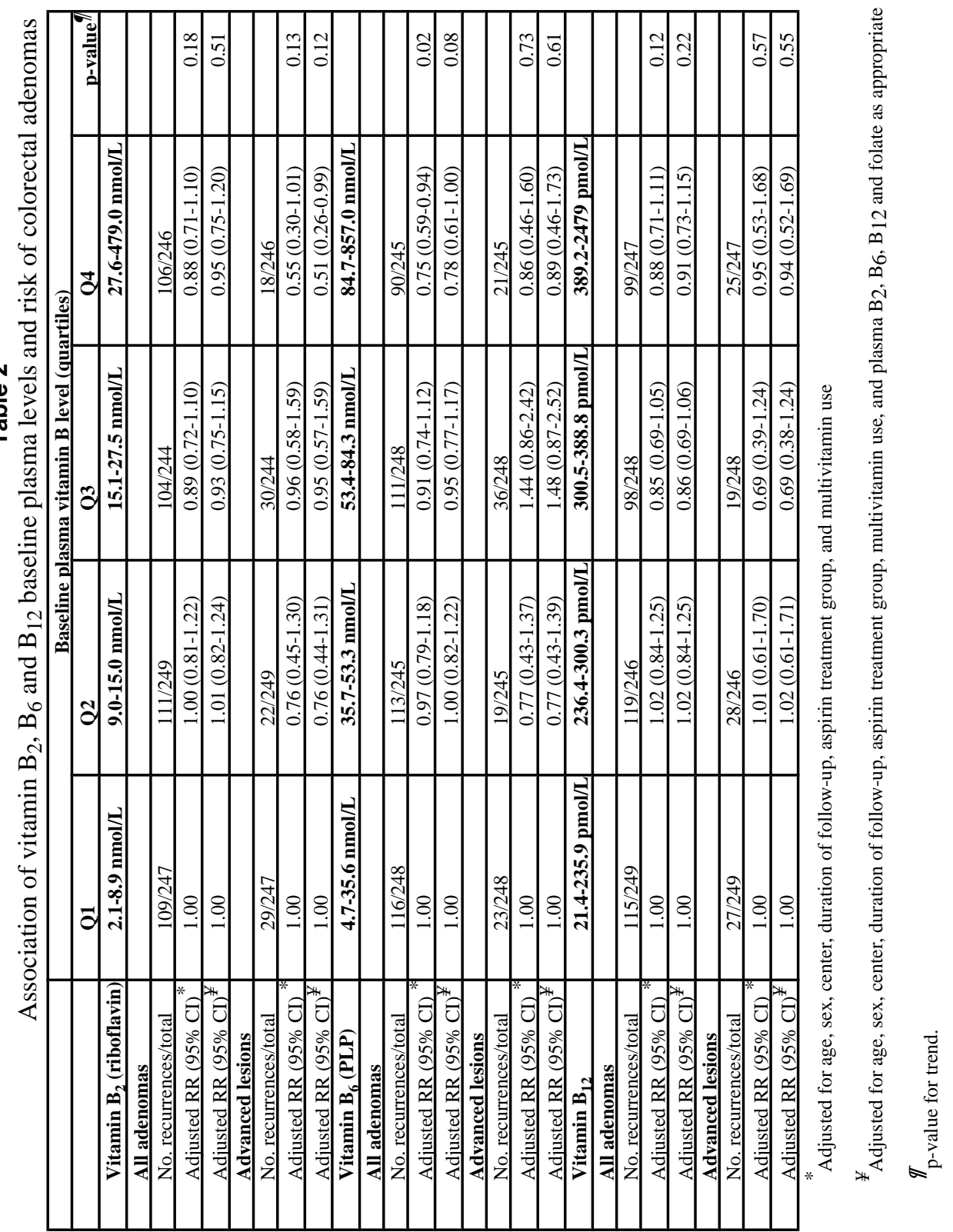




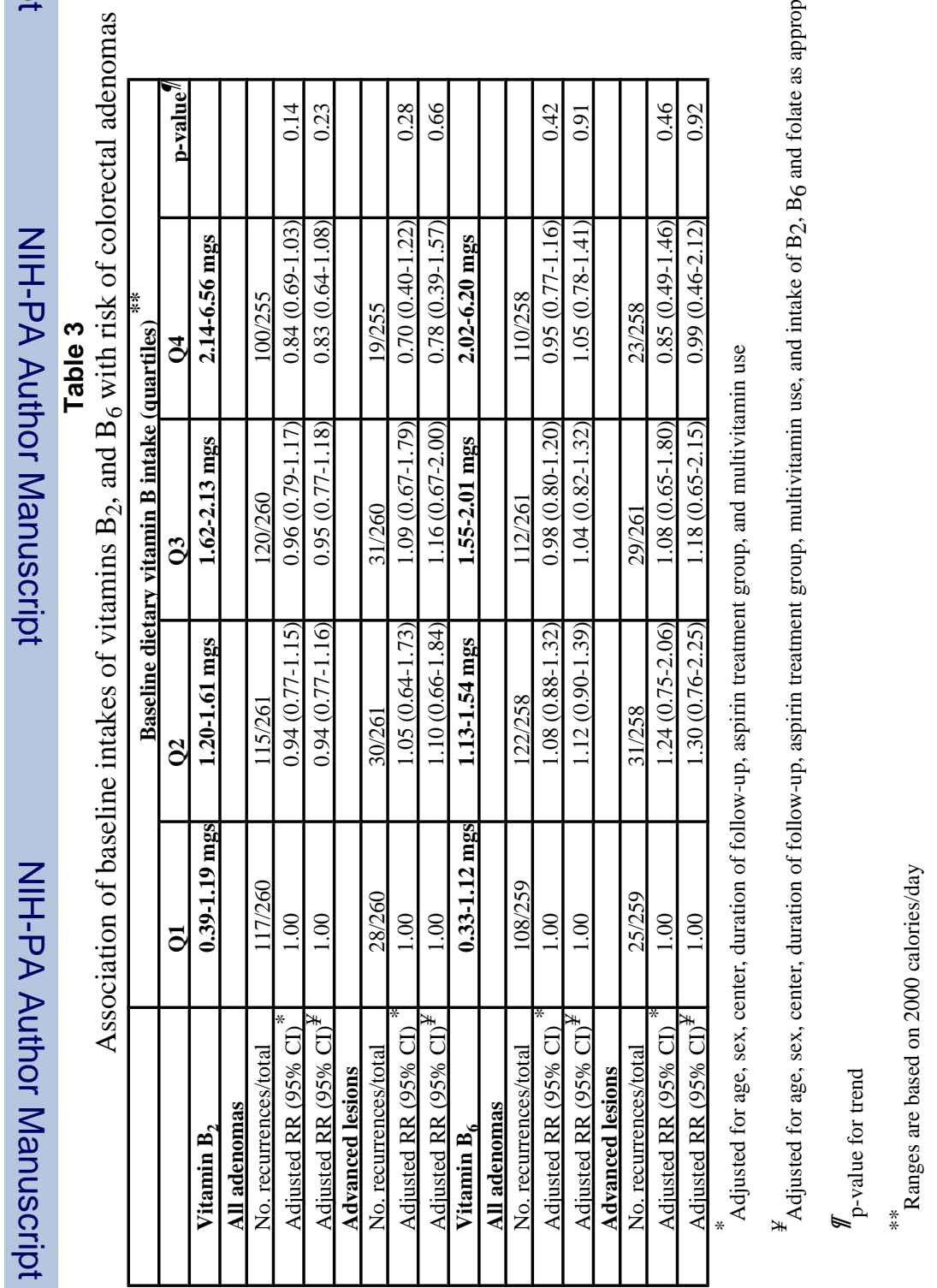




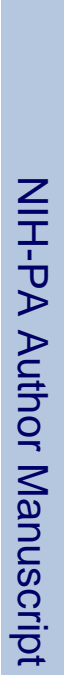

政

\begin{tabular}{|c|c|c|c|c|c|c|c|c|c|c|c|c|c|c|c|c|c|c|}
\hline$\dot{m}$ & $\stackrel{0}{0}$ & $\begin{array}{l}\infty \\
n \\
0\end{array}$ & $\stackrel{\infty}{n}$ & & & & $\stackrel{?}{\circ}$ & $\begin{array}{l}\stackrel{\partial}{0} \\
0\end{array}$ & $\stackrel{\infty}{\infty}$ & & & & $\bar{\sigma}$ & $\stackrel{0}{0}$ & ?ִ & & & \\
\hline$\dot{\Delta}$ & గొ & $\stackrel{\overbrace{}}{0}$ & గ్లి & $\stackrel{n}{0}$ & $\stackrel{0}{0}$ & $\hat{o}$ & $\pi$ & ?] & กี & f & $\stackrel{\infty}{\circ}$ & $\frac{5}{0}$ & $\begin{array}{l}\infty \\
\infty \\
0\end{array}$ & o. & $\frac{9}{0}$ & $\stackrel{0}{0}$ & $\begin{array}{l}\infty \\
\infty \\
0\end{array}$ & है: \\
\hline
\end{tabular}

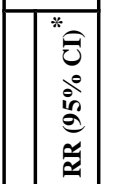
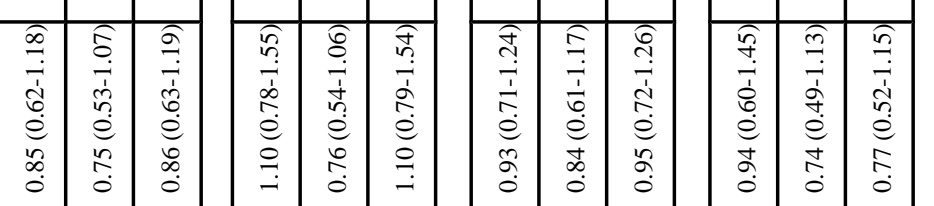

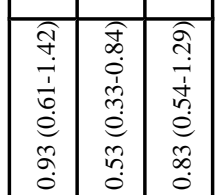

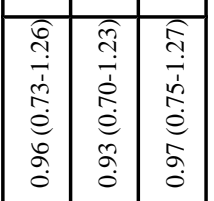

密

드를
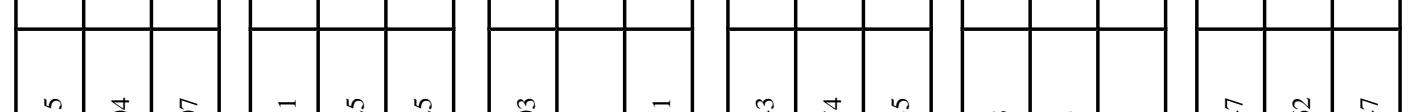

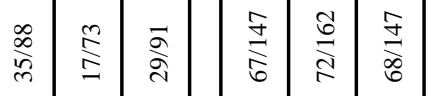

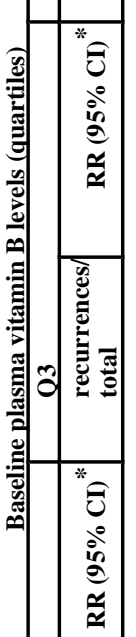

\begin{tabular}{|c|c|c|}
\hline $\bar{m}$ & ले & હิ) \\
\hline$\frac{1}{r}$ & I & $\dot{b}$ \\
\hline$\stackrel{e}{e}$ & $\stackrel{e}{\varrho}$ & $\stackrel{e}{e}$ \\
\hline$\hat{\sigma}$ & बे & $\begin{array}{l}\stackrel{0}{\infty} \\
0\end{array}$ \\
\hline
\end{tabular}

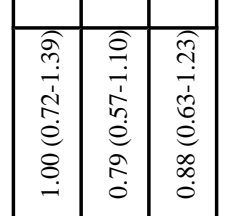

\begin{tabular}{|c|c|c|}
\hline$\widehat{\overbrace{}}$ & $\widehat{\vartheta}$ & $\infty$ \\
\hline$\vec{\infty}$ & $\bar{\curvearrowright}$ & $\overline{\mathfrak{I}}$ \\
\hline$\dot{e}$ & $\dot{e}$ & $\dot{e}$ \\
\hline ลे & ڤ్ & $\tilde{\delta}$ \\
\hline
\end{tabular}

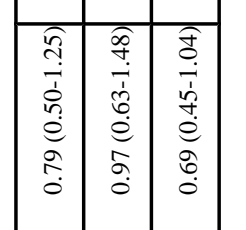

\begin{tabular}{|c|c|c|}
\hline$\tilde{n}$ & i & f \\
\hline$\vec{\infty}$ & $\stackrel{\infty}{n}$ & $\frac{1}{n}$ \\
\hline$\stackrel{e}{e}$ & $\stackrel{e}{e}$ & $\stackrel{\varrho}{e}$ \\
\hline$\stackrel{\infty}{0}$ & $\stackrel{\infty}{\circ}$ & $\stackrel{\infty}{0}$ \\
\hline
\end{tabular}

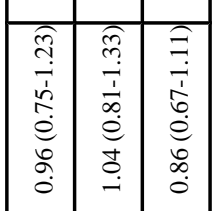

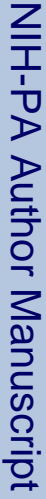
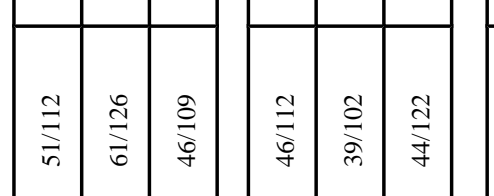

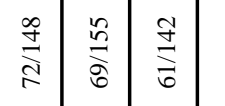

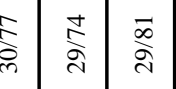

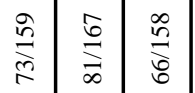

\begin{tabular}{|c|c|c|c|c|c|}
\hline ఠิ & ชิ & $\widehat{\widehat{\Upsilon}}$ & $\widehat{n}$ & 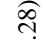 & $\stackrel{\infty}{\stackrel{\infty}{n}}$ \\
\hline & $\frac{1}{6}$ & $\bar{i}$ & $\frac{I}{\infty}$ & ’े & $\vec{\delta}$ \\
\hline & $\ddot{e}$ & $\stackrel{e}{0}$ & $\dot{e}$ & $\dot{e}$ & $\ddot{e}$ \\
\hline 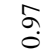 & \& & $\stackrel{\circ}{\circ}$ & $\stackrel{?}{\exists}$ & $\stackrel{\leftrightarrow}{o}$ & $\underset{\Xi}{ \pm}$ \\
\hline
\end{tabular}
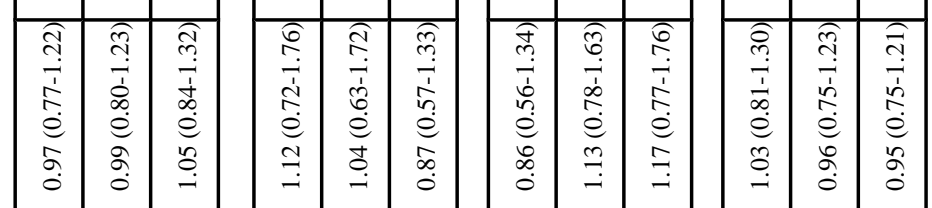

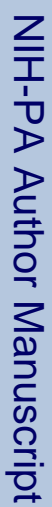

言

๓

20
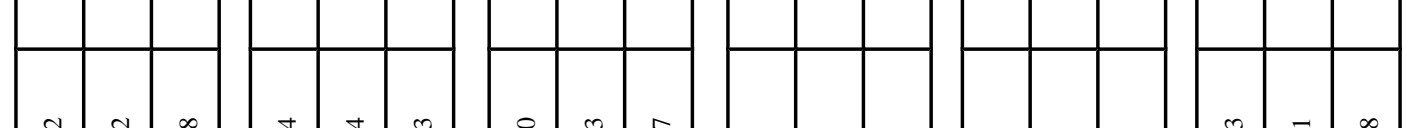

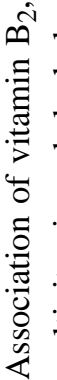

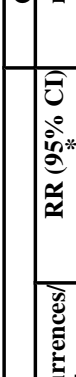

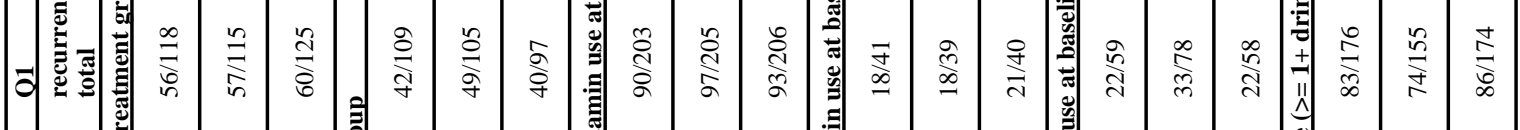

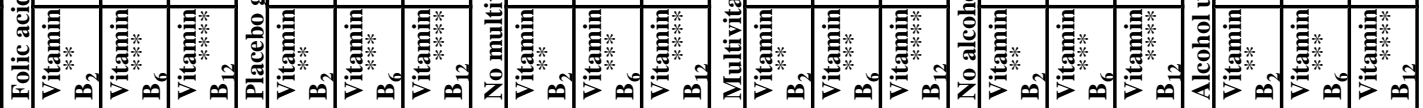


Table 5

Selected gene-vitamin B interactions and risk of colorectal adenomas

\begin{tabular}{|c|c|c|c|c|}
\hline & \multicolumn{4}{|c|}{ No. recurrences /total } \\
\hline Genotype & $\begin{array}{l}\text { Vitamin B level } \\
\text { below the median } \\
\text { (reference) }\end{array}$ & $\begin{array}{l}\text { Vitamin B level } \\
\text { above the median }\end{array}$ & $\begin{array}{c}\text { Adjusted RR (95\% } \\
\text { CI) }\end{array}$ & $P$ for interaction \\
\hline $\begin{array}{l}\text { Baseline plasma vitamin } \mathbf{B}_{2} \\
\text { (riboflavin) }\end{array}$ & $2.1-15.0 \mathrm{nmol} / \mathrm{L}$ & $15.1-479.0 \mathrm{nmol} / \mathrm{L}$ & & \\
\hline MTHFR-677 CC+C/T & $195 / 413$ & $179 / 416$ & $0.87(0.73-1.03)$ & \\
\hline MTHFR-677 T/T & $18 / 52$ & $19 / 44$ & $1.40(0.85-2.30)$ & 0.07 \\
\hline MTHFR-1298 A/A+A/C & $197 / 431$ & $178 / 416$ & $0.90(0.76-1.07)$ & \\
\hline MTHFR-1298 C/C & $16 / 35$ & $21 / 45$ & $0.92(0.56-1.54)$ & 0.94 \\
\hline Baseline plasma vitamin $\mathbf{B}_{6}$ (PLP) & $21.4-300.3 \mathrm{pmol} / \mathrm{L}$ & $300.5-2479 \mathrm{pmol} / \mathrm{L}$ & & \\
\hline CBS-1080 C/C+C/T & $182 / 403$ & $159 / 402$ & $0.90(0.75-1.08)$ & \\
\hline CBS-1080 T/T & $37 / 56$ & $32 / 62$ & $0.72(0.49-1.03)$ & 0.25 \\
\hline CBS-699 C/C+C/T & $195 / 404$ & $179 / 422$ & $0.89(0.75-1.06)$ & \\
\hline CBS-699 T/T & $25 / 57$ & $13 / 44$ & $0.67(0.40-1.13)$ & 0.30 \\
\hline MTHFR-677 CC+C/T & $196 / 410$ & $178 / 419$ & $0.90(0.76-1.07)$ & \\
\hline MTHFR-677 T/T & $24 / 51$ & $13 / 45$ & $0.66(0.39-1.10)$ & 0.25 \\
\hline Baseline plasma vitamin $\mathbf{B}_{12}$ & $4.7-53.3 \mathrm{nmol} / \mathrm{L}$ & $53.4-857.0 \mathrm{nmol} / \mathrm{L}$ & & \\
\hline MTR 2756-A/A & $72 / 155$ & $63 / 151$ & $0.92(0.71-1.20)$ & \\
\hline MTR 2756- A/G + G/G & $151 / 310$ & $127 / 314$ & $0.87(0.72-1.05)$ & 0.70 \\
\hline MTRR $66-\mathrm{A} / \mathrm{A}+\mathrm{A} / \mathrm{G}$ & $163 / 335$ & $139 / 342$ & $0.86(0.72-1.03)$ & \\
\hline MTRR 66-G/G & $59 / 129$ & $51 / 123$ & $0.96(0.72-1.29)$ & 0.50 \\
\hline MTHFR-677 CC+C/T & $198 / 411$ & $177 / 421$ & $0.90(0.77-1.07)$ & \\
\hline MTHFR-677 T/T & $24 / 52$ & $13 / 45$ & $0.69(0.41-1.17)$ & 0.33 \\
\hline
\end{tabular}

* Adjusted for age, sex, center, duration of follow-up, aspirin treatment group, multivitamin use and plasma B2, B6, B12 and folate as appropriate

${ }_{\mathrm{p} \text {-value for interaction }}$ 